\title{
Salegentibacter agarivorans sp. nov., a novel marine bacterium of the family Flavobacteriaceae isolated from the sponge Artemisina sp.
}

Correspondence

Olga I. Nedashkovskaya olganedashkovska@yahoo.com

\author{
Olga I. Nedashkovskaya, ${ }^{1}$ Seung Bum $\mathrm{Kim}^{2}{ }^{2}$ Marc Vancanneyt, ${ }^{3}$ \\ Dong Sung Shin, ${ }^{2}$ Anatoly M. Lysenko, ${ }^{4}$ Lyudmila S. Shevchenko, ${ }^{1}$ \\ Vladimir B. Krasokhin, ${ }^{1}$ Valery V. Mikhailov, ${ }^{1}$ Jean Swings ${ }^{3}$ \\ and Kyung Sook Bae ${ }^{5}$
}

\author{
${ }^{1}$ Pacific Institute of Bioorganic Chemistry of the Far-Eastern Branch of the Russian Academy \\ of Sciences, Pr. 100 Let Vladivostoku 159, 690022, Vladivostok, Russia \\ ${ }^{2}$ Department of Microbiology, School of Bioscience and Biotechnology, Chungnam National \\ University, 220 Gung-dong, Yusong, Daejon 305-764, Republic of Korea \\ ${ }^{3}$ BCCM/LMG Bacteria Collection, Laboratory of Microbiology, Ghent University, \\ Ledeganckstraat 35, B-9000 Ghent, Belgium \\ ${ }^{4}$ Institute of Microbiology of the Russian Academy of Sciences, Pr. 60 Let October 7/2, \\ Moscow, 117811, Russia \\ ${ }^{5}$ Korea Research Institute of Bioscience and Biotechnology, 52 Oun-Dong, Yusong, \\ Daejon 305-333, Republic of Korea
}

Bacteria belonging to the genus Salegentibacter, a member of the family Flavobacteriaceae, are aerobic, halotolerant or halophilic, pigmented yellow or yellow-orange and motile by gliding (McCammon \& Bowman, 2000). At present, there are three Salegentibacter species with validly published names: Salegentibacter salegens, formerly Flavobacterium salegens (Dobson et al., 1993), isolated from a meromictic lake in Antarctica; Salegentibacter holothuriorum, recovered from the edible holothurian Apostichopus japonicus in the Sea of Japan; and Salegentibacter mishustinae, isolated from the sea urchin Strongylocentrotus intermedius (McCammon \& Bowman, 2000; Nedashkovskaya et al., 2004, 2005). The genus Mesonia is the nearest phylogenetic neighbour of Salegentibacter species.

During the 29th cruise of the $R / V$ Akademician Oparin, a novel agar-decomposing bacterium, strain $\mathrm{KMM} 7019^{\mathrm{T}}$, was

The GenBank/EMBL/DDBJ accession number for the 16S rRNA gene sequence of strain KMM $7019^{\top}$ is DQ191176. isolated from a sponge (Artemisina sp.) collected in July 2003 near Onecotan Island, Kuril Islands, Sea of Okhotsk, Pacific Ocean, from a depth of $150 \mathrm{~m}$. For strain isolation, $0 \cdot 1 \mathrm{ml}$ tissue homogenate was transferred to marine agar (Difco) plates. After primary isolation and purification the strain was cultivated at $28{ }^{\circ} \mathrm{C}$ on the same medium and stored at $-80^{\circ} \mathrm{C}$ in marine broth (Difco) supplemented with $20 \%(\mathrm{v} / \mathrm{v})$ glycerol.

Genomic DNA extraction, PCRs and sequencing of the $16 \mathrm{~S}$ rRNA gene were performed according to published procedures (Kim et al., 1998). The sequence obtained was aligned, using PHYDIT, version 3.2 (http://plaza.snu.ac.kr/ jchun/ phydit/), with those of representative members of selected genera belonging to the family Flavobacteriaceae. Phylogenetic trees were inferred by using suitable programs of the PHYLIP package (Felsenstein, 1993). Phylogenetic distances were calculated from the models of Kimura (1980), and trees were constructed on the basis of the neighbour-joining (Saitou \& Nei, 1987) and maximum-likelihood (Felsenstein, 
1993) algorithms. Bootstrap analysis was performed with 1000 resampled datasets by using the SEQBOOT and CONSENSE programs of the PHYLIP package.

Analysis of 16S rRNA gene sequences indicated that strain KMM $7019^{\mathrm{T}}$ is a member of the family Flavobacteriaceae and that its nearest neighbours are Salegentibacter holothuriorum KMM $3524^{\mathrm{T}}$, Salegentibacter mishustinae $\mathrm{KMM} 6049^{\mathrm{T}}$ and Salegentibacter salegens DSM $5424^{\mathrm{T}}$, with sequence similarities of $97 \cdot 7-98 \cdot 0 \%$ (Fig. 1).

DNA was isolated by following the method of Marmur (1961), and the G $+C$ content was determined by using the thermal denaturation method (Marmur \& Doty, 1962). The DNA G + C content of the strain studied was $39 \cdot 2 \mathrm{~mol} \%$. DNA-DNA hybridization experiments were performed using the method described by De Ley et al. (1970). DNA-DNA relatedness levels between strain KMM $7019^{\mathrm{T}}$ and Salegentibacter species were in the range $27-31 \%$. These values are significantly below $70 \%$, and, consequently, the strain studied represents a novel species of the genus Salegentibacter (Wayne et al., 1987).

Analysis of fatty acid methyl esters was carried out according to the standard protocol of the Microbial Identification System (Microbial ID). All strains tested were grown on marine agar at $25^{\circ} \mathrm{C}$ for $48 \mathrm{~h}$. The predominant cellular fatty acids were $\mathrm{C}_{15: 1}$ iso $(12 \cdot 1 \%), \mathrm{C}_{15: 0}$ iso $(12 \cdot 3 \%), \mathrm{C}_{15: 0}$ anteiso $(7 \cdot 1 \%), \mathrm{C}_{15: 0}(5 \cdot 6 \%), \mathrm{C}_{17: 0}$ iso $3-\mathrm{OH}(9 \cdot 8 \%)$ and summed feature $3(12 \cdot 2 \%)$, comprising $\mathrm{C}_{16: 1} \omega 7 c$ and/or $\mathrm{C}_{15: 0}$ iso $2-\mathrm{OH}$. The complete fatty acid content of strain KMM $7019^{\mathrm{T}}$ is given in Table 1 and compared with that of other Salegentibacter species.

A phenotypic analysis was performed using methods described previously (Nedashkovskaya et al., 2003a, b). API ZYM strips (bioMérieux) and Microlog GN2 plates (Biolog) were also used to assess physiological and biochemical features; these were employed according to the manufacturers' instructions, except that the solution used for the bacterial suspension consisted of $1.5 \% \mathrm{NaCl}$ saline, and the strips and the microplates were incubated at $25^{\circ} \mathrm{C}$. Motility was determined as described by Bowman (2000).

The physiological, biochemical and morphological characteristics of strain KMM $7019^{\mathrm{T}}$ are listed in the species description and in Table 2. The phenotypic features of the strain tested are consistent with those of the Salegentibacter species (Table 2). However, strain KMM $7019^{\mathrm{T}}$ differs from all Salegentibacter species with validly published names by its ability to grow at $41{ }^{\circ} \mathrm{C}$, to hydrolyse agar, to form acid from L-arabinose, D-cellobiose and DL-xylose, to utilize L-arabinose, to move by means of gliding, and by its susceptibility to kanamycin and neomycin. Additional phenotypic traits also distinguish the strain studied from some of the Salegentibacter species (Table 2).

Thus, genomic divergences supported by phenotypic and chemotaxonomic data allow affiliation of strain KMM $7019^{\mathrm{T}}$ to the genus Salegentibacter, in which it forms a distinct lineage, as Salegentibacter agarivorans sp. nov.

\section{Description of Salegentibacter agarivorans sp. nov.}

Salegentibacter agarivorans (a.ga.r.i.vo'rans. N.L. n. agarum agar, algal polysaccharide; L. v. vorare to devour, to digest; N.L. part. adj. agarivorans agar-digesting).

Cells are Gram-negative, strictly aerobic, chemo-organotrophic, asporogenic rods $0 \cdot 5-0 \cdot 7 \mu \mathrm{m}$ wide and $2 \cdot 0-4 \cdot 7 \mu \mathrm{m}$ long and motile by gliding. Oxidase-, catalase-, $\beta$-galactosidaseand alkaline phosphatase-positive. Colonies are circular, convex, slimy, shiny with entire edges, sunken into the agar and $1-3 \mathrm{~mm}$ in diameter on marine agar 2216. Produces yellow, carotenoid, non-diffusible pigments. Flexirubintype pigments are absent. Grows in the presence of 1-18\% $\mathrm{NaCl}$; growth optimum observed at 2-4\% $\mathrm{NaCl}$. Growth

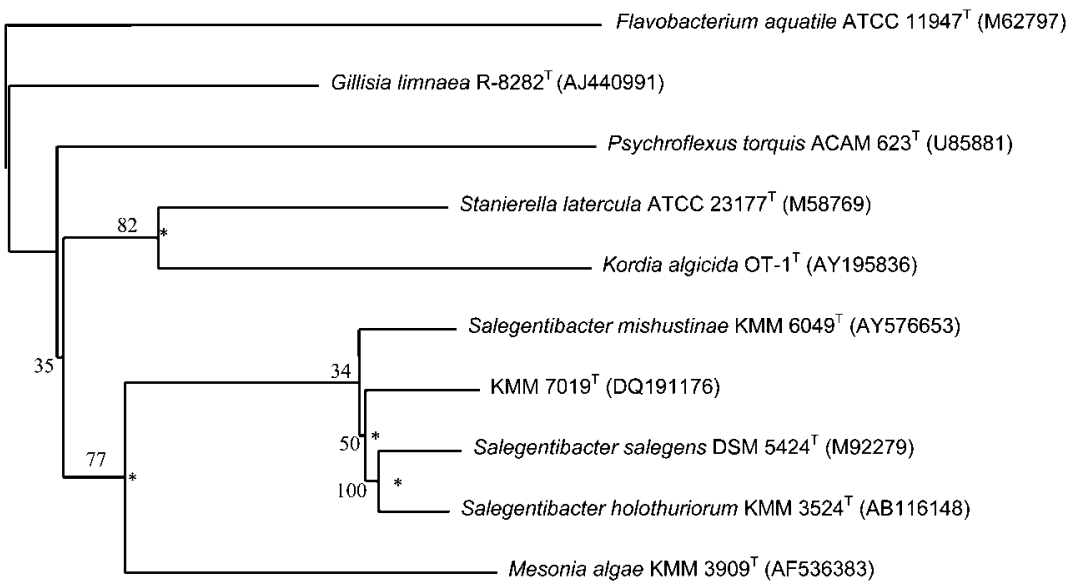

0.01
Fig. 1. Phylogenetic tree based on the $16 \mathrm{~S}$ rRNA gene sequences of KMM $7019^{\top}$ and related members of the family Flavobacteriaceae. Asterisks indicate branches that were also recovered in the maximum-likelihood algorithm. Numbers at nodes indicate levels of bootstrap support (\%) from 1000 resamplings. Bar, 0.01 substitutions per nucleotide position. 
Table 1. Cellular fatty acid content (\%) of the Salegentibacter species

Fatty acids amounting to less than $1 \%$ of the total in all strains studied are not listed. The fatty acid content of Salegentibacter holothuriorum KMM $3524^{\mathrm{T}}$ was not included in the table because it was determined for bacteria grown under conditions different from those used for the other species. Data are from Nedashkovskaya et al. (2003c, 2005) and this study. ND, Not detected.

\begin{tabular}{|c|c|c|c|}
\hline Fatty acid & $\begin{array}{c}\text { Salegentibacter } \\
\text { agarivorans } \\
\text { KMM } 7019^{\mathrm{T}}\end{array}$ & $\begin{array}{c}\text { Salegentibacter } \\
\text { mishustinae } \\
\text { KMM } 6049^{\mathrm{T}}\end{array}$ & 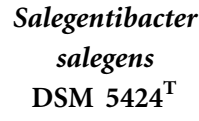 \\
\hline $\mathrm{C}_{15: 1}$ iso & $12 \cdot 1$ & $12 \cdot 3$ & $17 \cdot 7$ \\
\hline $\mathrm{C}_{15: 1}$ anteiso & $1 \cdot 9$ & $1 \cdot 3$ & $3 \cdot 5$ \\
\hline $\mathrm{C}_{15: 0}$ iso & $12 \cdot 3$ & $12 \cdot 1$ & $8 \cdot 5$ \\
\hline $\mathrm{C}_{15: 0}$ anteiso & $7 \cdot 1$ & $7 \cdot 9$ & $8 \cdot 5$ \\
\hline $\mathrm{C}_{15: 0}$ & $5 \cdot 6$ & $6 \cdot 7$ & $7 \cdot 6$ \\
\hline $\mathrm{C}_{15: 1} \omega 6 c$ & $2 \cdot 3$ & $2 \cdot 4$ & $5 \cdot 7$ \\
\hline $\mathrm{C}_{16: 1}$ iso & $1 \cdot 5$ & $1 \cdot 9$ & $2 \cdot 6$ \\
\hline $\mathrm{C}_{16: 0}$ iso & $2 \cdot 8$ & $4 \cdot 6$ & $3 \cdot 1$ \\
\hline $\mathrm{C}_{16: 0}$ & $\mathrm{ND}$ & $1 \cdot 8$ & ND \\
\hline $\mathrm{C}_{15: 0} 3-\mathrm{OH}$ iso & $3 \cdot 6$ & $2 \cdot 9$ & $2 \cdot 5$ \\
\hline $\mathrm{C}_{15: 0} 3-\mathrm{OH}$ & $2 \cdot 3$ & $2 \cdot 1$ & $3 \cdot 9$ \\
\hline $\mathrm{C}_{15: 0} 2-\mathrm{OH}$ & $3 \cdot 5$ & $2 \cdot 6$ & $2 \cdot 4$ \\
\hline $\mathrm{C}_{17: 1} \omega 9 c$ iso & $2 \cdot 5$ & $2 \cdot 2$ & $2 \cdot 0$ \\
\hline $\mathrm{C}_{17: 1} \omega 6 c$ & $3 \cdot 8$ & $3 \cdot 5$ & $4 \cdot 1$ \\
\hline $\mathrm{C}_{16: 0} 3-\mathrm{OH}$ iso & $3 \cdot 9$ & $4 \cdot 7$ & $5 \cdot 9$ \\
\hline $\mathrm{C}_{16: 0} 3-\mathrm{OH}$ & $1 \cdot 3$ & $0 \cdot 5$ & ND \\
\hline $\mathrm{C}_{17: 0} 3-\mathrm{OH}$ iso & $9 \cdot 8$ & $8 \cdot 6$ & $5 \cdot 9$ \\
\hline $\mathrm{C}_{17: 0} 2-\mathrm{OH}$ & $4 \cdot 5$ & $3 \cdot 1$ & $4 \cdot 7$ \\
\hline $\mathrm{C}_{18: 0}$ & $\mathrm{ND}$ & $1 \cdot 3$ & ND \\
\hline Summed feature $3^{*}$ & $12 \cdot 2$ & $7 \cdot 9$ & $6 \cdot 1$ \\
\hline
\end{tabular}

* Summed features consist of one or more fatty acids that could not be separated by the Microbial Identification System. Summed feature 3: $\mathrm{C}_{15: 0} 2-\mathrm{OH}$ iso and/or $\mathrm{C}_{16: 1} \omega 7 c$.

detected at $4-41{ }^{\circ} \mathrm{C}$, with an optimum at $28-32{ }^{\circ} \mathrm{C}$. The $\mathrm{pH}$ range for growth is $5 \cdot 7-10 \cdot 0$, with optimum growth occurring between $\mathrm{pH} 7 \cdot 5$ and $8 \cdot 3$. Hydrolyses agar, gelatin, starch, alginic acids, DNA and Tweens 20, 40 and 80, but not casein, cellulose (CM-cellulose and filter paper), chitin or urea. Forms acid from L-arabinose, D-cellobiose, D-fructose, L-fucose, D-galactose, D-glucose, DL-xylose, D-lactose, D-maltose, L-raffinose, D-sucrose and $\mathrm{N}$-acetylglucosamine, but not from L-rhamnose, L-sorbose, adonitol, dulcitol, glycerol, inositol, sorbitol or mannitol. Utilizes D-mannose, but not inositol, sorbitol, mannitol, citrate or malonate. In the Microlog GN2 plate, KMM $7019^{\mathrm{T}}$ utilizes $\alpha$-D-glucose, $\alpha$-lactose, sucrose, methyl pyruvate, monomethyl succinate, D-galactonic acid, D-gluconic acid, $\beta$-hydroxybutyric acid, $p$-hydroxyphenylacetic acid, itaconic acid, $\alpha$-ketoglutaric acid, DL-lactic acid, propionic acid, succinic acid, succinamic acid, alaninamide, L-alanyl glycine, L-asparagine, L-aspartic acid, L-glutamic acid, glycyl L-aspartic acid, L-phenylalanine, L-proline, L-pyroglutamic acid, L-threonine and urocanic acid. Does not utilize $\alpha$-cyclodextrin, dextrin, glycogen, $\mathrm{N}$-acetyl-D-galactosamine, adonitol, L-arabitol, i-erythritol, gentiobiose, myo-inositol, lactulose, D-mannitol, D-melibiose, methyl $\beta$-D-glucoside, psicose, D-sorbitol, D-trehalose, turanose, xylitol, acetic acid, cis-aconitic acid, citric acid, formic acid, D-galacturonic acid, D-glucosaminic acid, D-glucuronic acid, $\alpha$-hydroxybutyric acid, $\gamma$-hydroxybutyric acid, $\alpha$-ketobutyric acid, $\alpha$-ketovaleric acid, malonic acid, quinic acid, D-saccharic acid, sebacic acid, bromosuccinic acid, glucuronamide, D-alanine, L-alanine, glycyl L-glutamic acid, L-histidine, hydroxy-L-proline, L-leucine, L-ornithine, D-serine, L-serine, DL-carnitine, $\gamma$-aminobutyric acid, inosine, uridine, thymidine, phenylethylamine, putrescine, 2-aminoethanol, 2,3-butanediol, glycerol, DL- $\alpha$-glycerol phosphate, glucose 1-phosphate or glucose 6-phosphate. In the API ZYM gallery, KMM $7019^{\mathrm{T}}$ produces $\alpha$-galactosidase, $\beta$ galactosidase, alkaline phosphatase, acid phosphatase, esterase lipase (C8), leucine arylamidase, valine arylamidase, trypsin, $\alpha$-chymotrypsin, naphthol-AS-BI-phosphohydrolase, $\alpha$-glucosidase, $\beta$-glucosidase and $N$-acetyl- $\beta$-glucosaminidase, but not esterase (C4), lipase (C14), cystine arylamidase, $\beta$-glucuronidase, $\alpha$-mannosidase or $\alpha$-fucosidase. $\mathrm{H}_{2} \mathrm{~S}$ is produced. Nitrates are reduced to nitrites under oxic conditions. Does not produce indole or acetoin (Voges-Proskauer reaction). Susceptible to chloramphenicol, doxycycline, erythromycin, kanamycin, neomycin, oleandomycin and streptomycin. Resistant to ampicillin, 
Table 2. Phenotypic characteristics of Salegentibacter agarivorans sp. nov. KMM $7019^{\top}$ and other Salegentibacter species

Taxa: 1, Salegentibacter agarivorans sp. nov. (KMM 7019 ${ }^{\mathrm{T}}$; this study); 2, Salegentibacter holothuriorum (KMM 3524 ${ }^{\mathrm{T}}$; data from Nedashkovskaya et al., 2004); 3, Salegentibacter mishustinae (KMM $6049^{\mathrm{T}}$; data from Nedashkovskaya et al., 2005); 4, Salegentibacter salegens (DSM 5424 ${ }^{\mathrm{T}}$; data from Dobson et al., 1993; McCammon \& Bowman, 2000; and this study). All strains were positive for the following characteristics: respiratory metabolism; oxidase, catalase, $\beta$-galactosidase and alkaline phosphatase activities; hydrolysis of Tweens 20, 40 and 80, gelatin, elastin, starch and alginic acids; growth at $34{ }^{\circ} \mathrm{C}$ and with $8 \% \mathrm{NaCl}$; acid production from D-maltose; utilization of D-glucose and D-mannose; production of $\mathrm{H}_{2} \mathrm{~S}$; susceptibility to oleandomycin; and resistance to gentamicin and polymyxin B. All strains were negative for the following characteristics: hydrolysis of cellulose (CM-cellulose and filter paper), urea and chitin; acid production from L-rhamnose, L-sorbose, succinate, citrate, glycerol, adonitol, dulcitol, sorbitol, inositol and mannitol; utilization of inositol, mannitol, sorbitol, malonate and citrate; and production of indole and acetoin (Voges-Proskauer reaction).

\begin{tabular}{|c|c|c|c|c|}
\hline Characteristic & 1 & 2 & 3 & 4 \\
\hline Gliding motility & + & - & - & - \\
\hline $\mathrm{NaCl}$ requirement for growth & + & + & + & - \\
\hline Nitrate reduction & + & - & - & + \\
\hline Growth at $41^{\circ} \mathrm{C}$ & + & - & - & - \\
\hline Growth with $18 \% \mathrm{NaCl}$ & + & - & + & + \\
\hline \multicolumn{5}{|l|}{ Hydrolysis of: } \\
\hline Agar & + & - & - & - \\
\hline Casein & - & - & + & - \\
\hline DNA & + & + & - & + \\
\hline \multicolumn{5}{|l|}{ Acid production from: } \\
\hline L-Arabinose, DL-xylose, D-cellobiose & + & - & - & - \\
\hline D-Sucrose, L-raffinose & + & - & + & - \\
\hline D-Galactose, D-glucose & + & + & - & + \\
\hline D-Lactose, L-fucose, $N$-acetylglucosamine & + & + & - & - \\
\hline \multicolumn{5}{|l|}{ Utilization of: } \\
\hline L-Arabinose & + & - & - & - \\
\hline D-Sucrose & + & - & + & + \\
\hline D-Lactose & + & + & + & - \\
\hline \multicolumn{5}{|l|}{ Susceptibility to: } \\
\hline Ampicillin, benzylpenicillin, lincomycin, tetracycline & - & + & + & + \\
\hline Carbenicillin & - & + & - & + \\
\hline Kanamycin, neomycin & + & - & - & - \\
\hline Streptomycin & + & - & - & + \\
\hline DNA G $+\mathrm{C}$ content $(\mathrm{mol} \%)$ & $39 \cdot 2$ & $37 \cdot 5$ & $37 \cdot 5$ & $37 \cdot 8$ \\
\hline
\end{tabular}

benzylpenicillin, carbenicillin, lincomycin, gentamicin, tetracycline and polymyxin $\mathrm{B}$. The predominant cellular fatty acids are $\mathrm{C}_{15: 1}$ iso $(12 \cdot 1 \%), \mathrm{C}_{15: 0}$ iso $(12 \cdot 3 \%), \mathrm{C}_{15: 0}$ anteiso $(7 \cdot 1 \%), \mathrm{C}_{15: 0}(5 \cdot 6 \%), \mathrm{C}_{17: 0}$ iso $3-\mathrm{OH}(9 \cdot 8 \%)$ and summed feature $3(12 \cdot 2 \%)$, comprising $\mathrm{C}_{16: 1} \omega 7 c$ and/or $\mathrm{C}_{15: 0}$ iso $2-\mathrm{OH}$. The DNA G+C content is $39 \cdot 2 \mathrm{~mol} \%$.

The type strain, KMM $7019^{\mathrm{T}}\left(=\mathrm{KCTC} 12560^{\mathrm{T}}=\mathrm{LMG}\right.$ $23205^{\mathrm{T}}$ ), was isolated from a sponge (Artemisina sp.) collected near Onecotan Island, Kuril Islands, Sea of Okhotsk, Pacific Ocean.

\section{Acknowledgements}

This research was supported by grants from the Federal Agency for Science and Innovations of the Ministry for Education and Sciences of the Russian Federation (nos RI-26/109, 2-2.16 and 112/001/724), the Russian Foundation for Basic Research (no. 05-04-48211) and the Presidium of the Russian Academy of Sciences 'Molecular and Cell Biology'. K.S.B. acknowledges support from the KRIBB research initiative program. M.V. and J.S. acknowledge the Belgian Federal Public Planning Service - Science Policy.

\section{References}

Bowman, J. P. (2000). Description of Cellulophaga algicola sp. nov., isolated from the surfaces of Antarctic algae, and reclassification of Cytophaga uliginosa (ZoBell and Upham 1944) Reichenbach 1989 as Cellulophaga uliginosa comb. nov. Int J Syst Evol Microbiol 50, 1861-1868.

De Ley, J., Cattoir, H. \& Reynaerts, A. (1970). The quantitative measurement of DNA hybridization from renaturation rates. Eur J Biochem 12, 133-142. 
Dobson, S. J., Colwell, R. R., McMeekin, T. A. \& Franzmann, P. D. (1993). Direct sequencing of the polymerase chain reaction-amplified $16 \mathrm{~S}$ rRNA gene of Flavobacterium gondwanense sp. nov. and Flavobacterium salegens sp. nov., two new species from a hypersaline Antarctic lake. Int J Syst Bacteriol 43, 77-83.

Felsenstein, J. (1993). PHYLIP (phylogeny inference package), version 3.5c. Distributed by the author. Department of Genome Sciences, University of Washington, Seattle, WA, USA.

Kim, S. B., Falconer, C., Williams, E. \& Goodfellow, M. (1998). Streptomyces thermocarboxydovorans sp. nov. and Streptomyces thermocarboxydus sp. nov., two moderately thermophilic carboxydotrophic species isolated from soil. Int J Syst Bacteriol 48, 59-68.

Kimura, M. (1980). A simple method for estimating evolutionary rates of base substitutions through comparative studies of nucleotide sequences. J Mol Evol 16, 111-120.

Marmur, J. (1961). A procedure for the isolation of deoxyribonucleic acid from microorganisms. J Mol Biol 3, 208-218.

Marmur, J. \& Doty, P. (1962). Determination of the base composition of deoxyribonucleic acid from its thermal denaturation temperature. J Mol Biol 5, 109-118.

McCammon, S. A. \& Bowman, J. P. (2000). Taxonomy of Antarctic Flavobacterium species: description of Flavobacterium gillisiae sp. nov., Flavobacterium tegetincola sp. nov. and Flavobacterium xanthum sp. nov., nom. rev., and reclassification of [Flavobacterium] salegens as Salegentibacter salegens gen. nov., comb. nov. Int J Syst Evol Microbiol 50, 1055-1063.
Nedashkovskaya, O. I., Suzuki, M., Vysotskii, M. V. \& Mikhailov, V. V. (2003a). Reichenbachia agariperforans gen. nov., sp. nov., a novel marine bacterium in the Cytophaga-Flavobacterium-Bacteroides phylum. Int J Syst Evol Microbiol 53, 81-85.

Nedashkovskaya, O. I., Suzuki, M., Vysotskii, M. V. \& Mikhailov, V. V. (2003b). Vitellibacter vladivostokensis gen. nov., sp. nov., a new member of the phylum Cytophaga-Flavobacterium-Bacteroides. Int J Syst Evol Microbiol 53, 1281-1286.

Nedashkovskaya, O. I., Kim, S. B., Han, S. K. \& 7 other authors (2003c). Mesonia algae gen. nov., sp. nov., a novel marine bacterium of the family Flavobacteriaceae isolated from the green alga Acrosiphonia sonderi (Kütz) Kornm. Int J Syst Evol Microbiol 53, 1967-1971.

Nedashkovskaya, O. I., Suzuki, M., Vancanneyt, M., Cleenwerck, I., Zhukova, N. V., Vysotskii, M. V., Mikhailov, V. V. \& Swings, J. (2004). Salegentibacter holothuriorum sp. nov., isolated from the edible holothurian Apostichopus japonicus. Int J Syst Evol Microbiol 54, 1107-1110.

Nedashkovskaya, O. I., Kim, S. B., Lysenko, A. M., Mikhailov, V. V., Bae, K. S. \& Kim, I. S. (2005). Salegentibacter mishustinae sp. nov., isolated from the sea urchin Strongylocentrotus intermedius. Int J Syst Evol Microbiol 55, 235-238.

Saitou, N. \& Nei, M. (1987). The neighbor-joining method: a new method for reconstructing phylogenetic trees. Mol Biol Evol 4, 406-425.

Wayne, L. G., Brenner, D. J., Colwell, R. R. \& 9 other authors (1987). International Committee on Systematic Bacteriology. Report of the ad hoc committee on reconciliation of approaches to bacterial systematics. Int J Syst Bacteriol 37, 463-464. 